\title{
A RESPONSABILIDADE PELA PERDA DE UMA CHANCE: REFLEXÕES SOBRE SUA NATUREZA JURÍDICA QUE AINDA PREVALECEM
}

Henrique Avelino Lana ${ }^{1}$ César Augusto de Castro Fiúza ${ }^{2}$

\begin{abstract}
Resumo
Inicialmente será feita uma abordagem geral sobre a teoria da perda de uma chance e sua inserção na seara da responsabilidade civil. Após breve contextualização histórica e evolutiva, serão apresentadas algumas reflexões acerca de sua natureza jurídica, bem como obre sua quantificação, mediante fundamentos legais, jurisprudenciais e doutrinários. Metodologicamente, adotar-se-á a linha indutiva para a elaboração da tese, atentando-se à vertente jurídico-dogmática. Ao final, pretende-se denotar que se divide a doutrina e jurisprudência entre os que defendem o enquadramento da perda de uma chance como espécie de danos emergentes, lucros cessantes, como estritamente modalidade de dano moral ou, ainda, quando dotada esta de caráter patrimonial, como sendo algo intermediário entre os danos emergentes e os lucros cessantes. Ademais, pretende-se mostrar que é salutar a reflexão sobre como mensurar a chance perdida, considerando-se as vias de arbitramento e probabilidade. Não se almeja esgotar o tema, mas trazer questionamentos que parecem demonstrar que o assunto é mesmo muito instigante e merecedor de aprofundamento doutrinário e jurisprudencial cada vez maior.
\end{abstract}

Palavras-chave: Perda de uma chance; indenização; responsabilidade civil; Natureza Jurídica; Danos materiais; Danos extrapatrimoniais.

\section{INTRODUÇÃO}

A responsabilidade civil tem como finalidade primordial a indenização dos danos injustos e apresenta-se em contínua evolução, de modo a acompanhar as mudanças sociais.

Os tribunais vêm se deparando com casos em que o proponente teve retirada uma chance que possuía de auferir determinada vantagem ou de evitar um prejuízo. A retirada da chance tem como consequência um dano definitivo, o qual poderia não ter ocorrido se não fosse a conduta do ofensor.

Nestes casos, em princípio, a aplicação literal dos pressupostos clássicos da responsabilidade civil não tutelaria o dano sofrido pela vítima, haja vista a ausência de nexo de causalidade entre a conduta e o dano final.

\footnotetext{
${ }^{1}$ Doutor em Direito Privado pela PUC/MG. professor de cursos de graduação e pós graduação em Belo Horizonte / MG. E-mail: henrique@mpatrocinio.com.br

${ }^{2}$ Doutor em Direito pela UFMG. Professor de Direito Civil e Romano nos cursos de graduação e pósgraduação da Pontifícia Universidade Católica de Minas Gerais, Universidade Federal de Minas Gerais e daFUMEC. Professor colaborador da Universidade de Itaúna. E-mail: henrique@mpaladvogados.com.br
} 
Assim, a perda da chance, teoria criada pela jurisprudência francesa proporciona outra solução.

Ao que se nota, a teoria da perda de uma chance é exposta de forma superficial na maior parte dos livros e doutrinas clássicas, mas vem sendo objeto de um maior estudo recentemente, principalmente após as lides terem sido submetidas ao Superior Tribunal de Justiça.

As reflexões a seguir, abordarão a perda de uma chance no âmbito da responsabilidade subjetiva, decorrentes de condutas eivadas de negligência, imprudência ou imperícia, não tendo por escopo, desta forma, analisara aplicabilidade da teoria nas hipóteses de responsabilidade civil objetiva.

\section{ANOTAÇÕES SOBRE A PERDA DE UMA CHANCE}

Sabe-se que no início de sua aplicação, a perda de uma chance estava mais restrita aos casos de responsabilidade dos profissionais liberais, em especial médicos e advogados. Todavia, nos últimos dez anos foi crescente a sua aplicação, alcançando-se situações afetas ao direito do trabalho e direito administrativo.

A princípio, sempre que o dano for certo, restará configurado o dever do agente de indenizar de forma integral o dano causado, incluindo-se o que efetivamente se perdeu (danos emergentes) e o que se deixou de ganhar (lucros cessantes).

Mas há casos em que a vítima do ato ilícito pode vir a ser privada de obter um vantagem futura ou de evitar um dano.

A expressão perda de uma chance advém do francês perte d'une chance, que significa "perda de uma oportunidade". Entende-se como chance ou oportunidade a probabilidade de se obter um benefício futuro ou evitar uma perda.

Caio Mário da Silva Pereira, citando Yoes Chartier sintetiza que "a reparação pela perda de uma chance repousa em uma probabilidade e uma certeza; que a chance seria realizada e que a vantagem perdida resultaria em prejuízo." (PEREIRA, 2002, p. 42). Acerca da teoria, também leciona Sérgio Savi:

(...) hoje é possível visualizar um dano independentemente do resultado final. Se por um lado, a indenização do dano consistente na vitória perdida (na causa judicial, por exemplo), é inadmissível, ante a incerteza que lhe é inerente, por outro lado, não há como negar a existência de uma possibilidade de vitória, antes da ocorrência do fato danoso. Em relação à exclusão da responsabilidade de vitória poderá, frise-se dependendo do caso concreto, existir um dano jurídico certo e passível de indenização. (SAVI, 2012,p. 3)

É certo que a vantagem que não se concretizou, mas que poderia ter se concretizado, é aleatória. Logo, não mereceria seria reparada.

Porém, deverá ser indenizada a probabilidade que existia dessa vantagem se concretizar, ou seja, a chance perdida, já que esta sim era certa.

Quando se perde uma chance, existe uma certeza que embasa a sua reparação, qual seja, a de que era 
provável se alcançar o resultado final.

Há a incerteza no prejuízo e certeza na probabilidade.

É possível dizer que os elementos que caracterizam a perda de uma chance são: a conduta do agente; um resultado que se perdeu, o qual pode ser caracterizado como dano; o nexo causal entre a conduta e as chances que se perderam.

Como se nota, para a responsabilização pela perda de uma chance devem estar presentes elementos básicos da responsabilidade civil. Mas, porém, o dano e o nexo casal são analisados através de uma nova perspectiva, pois neste caso trata-se de uma chance perdida, que não pode em hipótese alguma ser meramente hipotética.

Um bom exemplo é dado por Rafael Peteffi (2013, p. 10), em que cita-se o exemplo de um famoso peão que foi impedido de participar da etapa final de um rodeio devido à falta de pagamento da respectiva inscrição no evento, que deveria ter sido realizada pelo seu agente. Repare-se que não se observa o nexo de causalidade necessário entre a falha do agente e a perda da vantagem esperada pelo peão, que corresponderia ao prêmio concedido ao vencedor da competição. Afinal, o peão poderia ficar sem qualquer premiação, mesmo que tivesse participado da fase final do rodeio, pois vários fatores aleatórios poderiam causar a perda da vantagem esperada, dentre eles, por exemplo, a dificuldade da prova ou habilidade dos outros competidores.

É preciso se averiguar quais seriam as chances de aprovação do referido peão e quais foram subtraídas de maneira culposa pelo relapso agente. Foi este cenário de probabilidade da chance perdida, que ensejou a criação de uma nova categoria de dano indenizável, quais sejam, as chances perdidas.

Para a correta compreensão da teoria da perda de uma chance, assim como propôs seus criadores, façamos uma breve análise da sua evolução e origem.

\section{Um pouco sobre a evolução da teoria da perda de uma chance}

Sua origem foi no direito francês, especificamente na seara da responsabilidade médica, onde houve um maior estudo do tema por parte da doutrina e da jurisprudência.Em razão da maior dedicação ao assunto neste país, passou-se a defender a existência de uma espécie de dano diverso do resultado final, consistente na perda da possibilidade de se conseguir determinada vantagem, e não pela perda da própria vantagem esperada.

Houve ensejo a acirrados embates doutrinários, que acabaram por influenciar a própria Corte Francesa em suas decisões, as quais, ao adotar a teoria, passou a conceder indenizações neste sentido.

Ao que parece pelos relatos, a consolidação da aplicação deste instituto tem início com decisão da Corte de cassação que, em 1965, qual a condenou um profissional da saúde a reparar a chamada pertedúne chance de guerison ou de survie do paciente - perda de uma chance de cura ou sobrevivência de seu paciente (AGUIAR 
JÚNIOR 3 apud GONDIM, 2005, p. 22). Esta decisão analisava um recurso que tinha como objeto de irresignação a responsabilidade de um médico que, acusado por erro de diagnóstico, teria retirado da vítima as chances de cura de que esta dispunha.

Dessa forma, em face da dificuldade de se afirmar que o dano verificou-se por ato comissivo ou omissivo do médico, a Corte de Cassação Francesa entendeu que o prejuízo consistiu na perda de uma possibilidade de cura e condenou o médico ao pagamento de indenização pela oportunidade que foi retirada da vítima.

A partir dessa nova posição, ocorreram outras decisões proferidas pela referida Corte que aplicaram a mesma teoria, consolidando-se este entendimento perante a Corte de Cassação Francesa.

Há certo pioneirismo do ordenamento jurídico francês que, dentro da família romano-germânica, configurou-se como o sistema mais evoluído no trato da teoria da perda de uma chance.

Nesta esteira, na França, a atividade criadora dos juízes franceses alargou o campo de aplicação deste conceito, e hoje, a perda de uma chance é observada tanto nos danos advindos descumprimento contratual, quanto naqueles gerados pelos atos propriamente ilícitos, seja a responsabilidade subjetiva como objetiva.

\section{A aplicação da teoria no direito brasileiro}

No Brasil, com a entrada em vigor do Código Civil de 2002 não restam mais dúvidas acerca do ampliado conceito de dano adotado pela legislação nacional, vez que não há limitação aos tipos de danos indenizáveis, ressalvando-se tão somente a impossibilidade de reparação de danos hipotéticos, que não é o caso da perda de uma chance. É o que se percebe da análise do art. 186 e 927 do CC, que deixa margem a uma larga possibilidade de reparação de danos injustos.

Vê-se que emana do art. $927^{4}$ do Código Civil o princípio da reparabilidade integral dos danos, o qual acaba por reforçar a admissibilidade pela perda de uma chance.

Desta forma, o nosso atual direito civil decorre de um código que oferece ao julgador maior liberdade para interpretar o direito positivado, permitindo que este aplique as normas jurídicas levando em conta a peculiaridade de cada caso concreto. Isso possibilita uma resposta justa aos jurisdicionados, o que, evidentemente, exige do operador maior conhecimento e responsabilidade.

O princípio da reparabilidade garante o equilíbrio entre o dano e a reparação. Desta forma, o retorno ao status quo ante, sempre que possível, será determinado, para que assim seja assegurado o bem estar social que deve prevalecer entre os indivíduos de uma sociedade.

Veja-se que a possibilidade de indenização pela perda de uma chance é tutelada ainda no ordenamento

\footnotetext{
${ }^{3}$ AGUIAR JÚNIOR, Rui Rosado de. Responsabilidade civil do médico. RT718/27. São Paulo: Revista dos Tribunais, 1995. ${ }^{4}$ Art. 927. Aquele que, por ato ilícito (arts. 186 e 187), causar dano a outrem, fica obrigado a repará-lo.
} 
brasileiro pelo art. $5^{\circ}$, inciso $\mathrm{V}$ da $\mathrm{CF} / 88^{5}$, cláusula geral da responsabilidade em nossa carta magna, que dispõe ser assegurado o direito de resposta, proporcional ao agravo, além da indenização por dano material, moral ou à imagem. Deste preceito decorre que quem causar dano a outrem fica obrigado a repará-lo.

Nesta teoria, importante destacar que não se pode deixar de indenizar alguém em razão da impossibilidade de se comprovar que o resultado final ocorreria. Assim, visualiza-se um dano que advém da oportunidade retirada.

A aplicação desta teoria não vai de encontro com o disposto no art. $403^{6}$ do CC/02, o qual afasta a possibilidade de indenização dos danos meramente hipotéticos, pois a chance passível de indenização é somente aquela que se caracteriza por ser séria e real.

Neste teoria, a certeza do dano encontra-se na perda de uma chance de se obter uma vantagem ou evitar um prejuízo. Esta sim que é objeto da indenização a ser pleiteada.

Caio Mário da Silva Pereira já afirmava que a chance perdida será indenizável desde que, mais do que uma possibilidade, haja uma "probabilidade suficiente", ou seja, a chance tem que ser séria e real (PEREIRA, 2002).

Nota-se que negar a indenização pela chance perdida seria um retrocesso à evolução da responsabilidade civil, que tem hoje como fundamento os princípios da dignidade da pessoa humana, da solidariedade social e da justiça distributiva, em consonância com os preceitos contidos na nossa Carta Magna.

\section{Algumas observações sobre o caso "Show do milhão"}

O Superior Tribunal de Justiça julgou caso paradigmático, no qual foram aplicadas as premissas da teoria da perda de uma chance, caso este amplamente conhecido como "show do milhão"7, programa apresentado por Sílvio Santos no canal SBT.

Consistia em uma série de questões de múltiplas escolhas, sendo que para cada acerto o participante acumulava um prêmio em dinheiro, até a quantia de $\mathrm{R} \$ 500.000,00$ (quinhentos mil reais). Neste momento então, o participante teria duas opções: parar de jogar e levar o prêmio conquistado até então, no valor de R\$ 500.000,00 (quinhentos mil reais), ou responder uma última questão no valor de $\mathrm{R} \$ 1.000 .000,00$ (um milhão de reais), na qual correria o risco de perder todo o montante até aquele momento adquirido caso errasse a chamada "pergunta do milhão".

\footnotetext{
${ }^{5} \mathrm{Art} .5^{\circ}, \mathrm{V}$ - é assegurado o direito de resposta, proporcional ao agravo, além da indenização por dano material, moral ou à imagem;

${ }^{6}$ Art. 403. Ainda que a inexecução resulte de dolo do devedor, as perdas e danos só incluem os prejuízos efetivos e os lucros cessantes por efeito dela direto e imediato, sem prejuízo do disposto na lei processual.

${ }^{7}$ BRASIL. Superior Tribunal de Justiça. REsp 788.459/BA, Recorrente: BF Utilidades Domésticas Ltda., Recorrido: Ana Lúcia Serbeto de Freitas Matos, Rel. Min. Fernando Gonçalves, julgado em 08/11/2005.
} 
A autora da ação participou do programa até a última etapa na qual a pergunta valeria a quantia de $\mathrm{R} \$$ 1.000.000,00, e por um erro na elaboração do programa ao elaborar a pergunta, acabou por desistir de oferecer a resposta e deixou o programa com a premiação que havia acumulado até então ( $\$$ \$ 500.000,00).

E a pergunta formulada foi a seguinte: "A Constituição reconhece direitos aos índios de quanto do território brasileiro? Resposta: (a) 22\%; (b) 2\%; (c) 4\%; (d) 10\%.

De acordo com a organização do programa, a alternativa correta seria a letra "d". Todavia, a Constituição Federal não reserva percentual do território nacional aos povos indígenas, mas apenas se limita a reconhecer os direitos originários dos índios sobre "as terras que tradicionalmente ocupam”, conforme seu artigo 231.

Neste contexto, a jogadora ajuizou ação indenizatória, pleiteando todo o valor perdido e argumentou que havia sido privada da chance de ganhar o prêmio devido à má formulação da pergunta, pois esta não continha alternativa correta.

No Juízo de primeira instância, acolheu-se a teoria da responsabilidade civil pela perda da chance, condenando-se o réu ao pagamento de R 500.000,00. Em segunda instância, esta decisão foi mantida pelo Tribunal de Justiça da Bahia.

Já o Superior Tribunal de Justiça reconheceu, por decisão unânime de sua 4a turma, a perda da chance, e acolheu apenas em parte o recurso interposto pelo réu. Logo, ao proporcionar uma solução matemática para o impasse, entendeu o STJ que se a questão tivesse sido formulada corretamente, a autora teria direito ao premio de um milhão de reais caso acertasse a resposta correta. E, que, considerando-se que a pergunta possuía quatro alternativas, entendeu o STJ que suas chances de acerto eram de $25 \%$, razão pela qual reduziu a condenação para o valor de apenas R\$125.000,00. Veja-se:

RECURSO ESPECIAL. INDENIZAÇAO. IMPROPRIEDADE DE PERGUNTA FORMULADA EM PROGRAMA DE TELEVISAO. PERDA DA OPORTUNIDADE.

1. O questionamento, em programa de perguntas e respostas, pela televisão, sem viabilidade lógica, uma vez que a Constituição Federal não indica percentual relativo às terras reservadas aos índios, acarreta, como decidido pelas instâncias ordinárias, a impossibilidade da prestação por culpa do devedor, impondo o dever de ressarcir o participante pelo que razoavelmente haja deixado de lucrar, pela perda da oportunidade.

2. Recurso conhecido e, em parte, provido. (REsp 788.459/BA, Recorrente: BF Utilidades Domésticas Ltda., Recorrido: Ana Lúcia Serbeto de Freitas Matos, Rel. Min. Fernando Gonçalves, julgado em 08/11/2005.)

Ao que parece, o STJ destacou que a incerteza do acerto da questão impossibilitava a condenação do Réu ao pagamento total da indenização pleiteada (lucros cessantes). O STJ reconheceu a condenação, mesmo que em parte, devido à perda da oportunidade de alcançar o resultado, e não devido à perda do resultado final.

Assim, a autora possuía uma chance efetiva de ganhar o prêmio, e o ato do Réu (má formulação da questão) tirou-lhe a chance de ganhar o premio máximo. 


\section{Reflexões sobre sua natureza jurídica}

Nota-se que se dividem os autores entre os que defendem o enquadramento da perda de uma chance como espécie de danos emergentes ${ }^{8}$, lucros cessantes ${ }^{9}$, outros entendem ser estritamente modalidade de dano moral ${ }^{10} \mathrm{e}$, ainda, os que colocam a teoria da perda da chance, quando dotada esta de caráter patrimonial, como algo intermediário entre os danos emergentes e os lucros cessantes.

Percebe-se que o enquadramento da teoria da perda de uma chance não é questão unânime na doutrina.

A que título deve ser concedida a perda de uma chance? Por dano moral ou material? E neste último caso, a título de dano emergente ou lucro cessante? Essa questão é também controvertida tanto na doutrina como na jurisprudência. Em muitas oportunidades os tribunais indenizam a perda de uma chance, ainda que não se refiram à expressão, a título de lucros cessantes; outras vezes como dano moral.

(...)A jurisprudência, repita-se, ainda não firmou entendimento sobre essa questão; ora a indenização pela perda de uma chance é concedida a título de dano moral, ora a título de lucros cessantes e, o que é pior, ora pela perda da própria vantagem e não pela perda da oportunidade de obter vantagem, com o que se acaba por transformar a perda em realidade. (CAVALIERI FILHO, 2008, p. 77)

Diante deste contexto, a comissão de Responsabilidade Civil, na V jornada de Direito Civil, promovida em 2011 pelo Centro de Estudos Judiciários (CEJ), órgão do Conselho da Justiça Federal (CJF),aprovou enunciado relativo à teoria da perda de uma chance, de autoria de Rafael Peteffi da Silva, que assim dispõe:

Art. 927. A responsabilidade civil pela perda de uma chance não se limita à categoria dos danos extrapatrimoniais, pois a chance perdida pode apresentar também a natureza jurídica de dano patrimonial, conforme as circunstâncias do caso concreto. A chance deve ser séria e real, não ficando adstrita a percentuais apriorísticos.

Sendo assim, não obstante as válidas confusões atinentes à aplicação da teoria nos casos concretos, é possível dizer que o entendimento que vem prevalecendo é o de que a teoria da perda de uma chance não se circunscreve apenas à seara dos danos morais, pois pode, dependendo do caso concreto, também apresentar feição de dano patrimonial.

Neste sentido, a ministra Nancy Andrigui, em acórdão que tratou da responsabilidade civil de advogado que negligentemente perdeu o prazo de recurso de apelação em favor de seu cliente, reconheceu a possibilidade de ensejar tanto danos de natureza patrimonial quanto extrapatrimonial.

PROCESSUAL CIVIL E DIREITO CIVIL. RESPONSABILIDADE DE ADVOGADO PELA PERDA DO PRAZO DE APELAÇÃO. TEORIA DA PERDA DA CHANCE.

\footnotetext{
${ }^{8}$ SAVI, Sérgio. Responsabilidade civil por perda de uma chance. São Paulo: Atlas, 2006, p. 56.

${ }^{9}$ Neste sentido: JOSÉ DE AGUIAR DIAS. Da Responsabilidade Civil, 10 ed., Rio de Janeiro: Forense, 1995, v. 2, p. 721, nota 33 apud SERGIO SAVI, op. cit., p. 39. J. M. CARVALHO SANTOS, Código Civil Brasileiro Interpretado, Rio de Janeiro: Freitas Bastos, 1956, v. XXI, p. 321-322 apud SERGIO SAVI, op. cit., p. 39.CAVALIERI FILHO, Sérgio. Programa de responsabilidade civil. 9.ed. São Paulo. Atlas, 2008, p.79.

${ }^{10}$ ANTÔNIO JEOVÁ DOS SANTOS. Dano Moral Indenizável, 2 ed., São Paulo: Lejus, 1999, p.110 apud SERGIO SAVI, op. cit,, p. 42.
} 


\begin{abstract}
APLICAÇÃO. RECURSO ESPECIAL. ADMISSIBILIDADE. DEFICIÊNCIA NA FUNDAMENTAÇÃO. NECESSIDADE DE REVISÃO DO CONTEXTO FÁTICOPROBATÓRIO. SÚMULA 7, STJ. APLICAÇÃO.

- A responsabilidade do advogado na condução da defesa processual de seu cliente é de ordem contratual. Embora não responda pelo resultado, o advogado é obrigado a aplicar toda a sua diligência habitual no exercício do mandato.

- Ao perder, de forma negligente, o prazo para a interposição de apelação, recurso cabível na hipótese e desejado pelo mandante, o advogado frustra as chances de êxito de seu cliente. Responde, portanto, pela perda da probabilidade de sucesso no recurso, desde que tal chance seja séria e real. Não se trata, portanto, de reparar a perda de "uma simples esperança subjetiva", nem tampouco de conferir ao lesado a integralidade do que esperava ter caso obtivesse êxito ao usufruir plenamente de sua chance.

- A perda da chance se aplica tanto aos danos materiais quanto aos danos morais.- A hipótese revela, no entanto, que os danos materiais ora pleiteados já tinham sido objeto de ações autônomas e que o dano moral não pode ser majorado por deficiência na fundamentação do recurso especial.- A pretensão de simples reexame de prova não enseja recurso especial. Aplicação da Súmula 7, STJ.- Não se conhece do Especial quando a decisão recorrida assenta em mais de um fundamento suficiente e o recurso não abrange todos eles. Súmula 283, STF.
\end{abstract}

Recurso Especial não conhecido.

(STJ, Recurso Especial n 1.079.185 MG, Terceira Turma, Rel. Ministra Nancy Andrighi, julgado em 11/11/2008, DJ em 4/8/2009.)

Nota-se que a ministra Nancy Andrighi se posiciona no sentido de que a perda de uma chance poderia,

além de apresentar natureza de dano patrimonial, agregar também, por vezes, natureza extrapatrimonial.

No mesmo sentido, as recentes decisões:

ADMINISTRATIVO E PROCESSUAL CIVIL. AGRAVO INTERNO NO RECURSO ESPECIAL. RESPONSABILIDADE CIVIL DO ESTADO. DANO MORAL. TEORIA DA PERDA DE UMA CHANCE. MORTE DE PACIENTE, EM TRATAMENTO DE CÂNCER, EM RAZÃO DA INTERRUPÇÃO DO FORNECIMENTO DO FÁRMACO, PELO ESTADO. ALEGADA NEGATIVA DE PRESTAÇÃO JURISDICIONAL. DEFICIÊNCIA DE FUNDAMENTAÇÃO. SÚMULA 284/STF. ACÓRDÃO BASEADO EM FUNDAMENTO CONSTITUCIONAL. IMPOSSIBILIDADE DE APRECIAÇÃO DA MATÉRIA, EM SEDE DE RECURSO ESPECIAL, SOB PENA DE USURPAÇÃO DA COMPETÊNCIA DO STF. ACÓRDÃO QUE, À LUZ DAS PROVAS DOS AUTOS, CONCLUIU PELA EXISTÊNCIA DE NEXO DE CAUSALIDADE ENTRE A OMISSÃO DO ESTADO E A MORTE DO PAI DOS AUTORES. REEXAME. SÚMULA 7/STJ. PRETENDIDA REDUÇÃO DO QUANTUM INDENIZATÓRIO. IMPOSSIBILIDADE DE REVISÃO, NA VIA ESPECIAL. SÚMULA 7/STJ. AGRAVO INTERNO IMPROVIDO.

I. Agravo interno aviado contra decisão publicada em 19/12/2016, que, por sua vez, julgara recurso interposto contra decisum publicado na vigência do CPC/73. II. Na origem, trata-se de ação de indenização por danos morais e materiais, proposta por Joelson de Almeida Souza, Jairo de Almeida Souza, Jailson de Almeida Souza e Joaquim de Almeida Souza, em desfavor do Estado do Acre, em decorrência da não disponibilização de medicamento para tratamento de câncer, na rede pública estadual de saúde, resultando no óbito de seu genitor.

III. Quanto à alegação de negativa de prestação jurisdicional, verifica-se que, apesar de apontar como violado o art. 535 do $\mathrm{CPC} / 73$, o agravante não evidencia qualquer vício, no acórdão recorrido, deixando de demonstrar no que consistiu a alegada ofensa ao citado 
dispositivo, atraindo, por analogia, a incidência da Súmula 284 do Supremo Tribunal Federal ("É inadmissível o recurso extraordinário, quando a deficiência na sua fundamentação não permitir a exata compreensão da controvérsia"). Nesse sentido: STJ, AgRg no AREsp 422.907/RJ, Rel. Ministra ELIANA CALMON, SEGUNDA TURMA, DJe de 18/12/2013; AgRg no AREsp 75.356/SC, Rel. Ministro SÉRGIO KUKINA, PRIMEIRA TURMA, DJe de 21/10/2013. IV. No mérito, o Tribunal de origem decidiu a controvérsia, acerca da responsabilidade civil do Estado, sob o enfoque eminentemente constitucional, o que torna inviável a análise da questão, no mérito, em sede de Recurso Especial, sob pena de usurpação da competência do STF. Precedentes do STJ (AgRg no AREsp 584.240/RS, Rel. Ministro BENEDITO GONÇALVES, PRIMEIRA TURMA, DJe de 03/12/2014; AgRg no REsp 1.473.025/PR, Rel. Ministro HUMBERTO MARTINS, SEGUNDA TURMA, DJe de 03/12/2014). V. Ademais, o Tribunal de origem manteve a sentença de parcial procedência, concluindo, à luz das provas dos autos, que "há nexo de causalidade entre a conduta omissiva e a precoce morte do Paciente, de quem lhe foi retirada a chance de uma sobrevida, não havendo que se falar em caso fortuito, sequer comprovado pelo Estado". Ainda segundo o acórdão de 20 Grau, "a conduta omissiva do Estado em não fornecer o medicamento impediu que o enfermo tivesse a possibilidade de um benefício futuro provável, consubstanciado na esperança de controle da evolução da doença". Conclusão em sentido contrário, demandaria, inarredavelmente, o revolvimento do acervo fático-probatório dos autos, o que é inviável, em sede de Recurso Especial, em face da Súmula 7 desta Corte.

VI. No que tange ao quantum indenizatório, "a jurisprudência do Superior Tribunal de Justiça é no sentido de que a revisão dos valores fixados a título de danos morais somente é possível quando exorbitante ou insignificante, em flagrante violação aos princípios da razoabilidade e da proporcionalidade, o que não é o caso dos autos. A verificação da razoabilidade do quantum indenizatório esbarra no óbice da Súmula 7/STJ" (STJ, AgInt no AREsp 927.090/SC, Rel. Ministro HERMAN BENJAMIN, SEGUNDA TURMA, DJe de $08 / 11 / 2016$ ).

VII. No caso, o Tribunal de origem, à luz das provas dos autos, fixou a indenização por danos morais em R\$ 100.000,00 (cem mil reais), a ser dividido pelos quatro autores, quantum que não se mostra excessivo, diante das peculiaridades da causa, expostas no acórdão recorrido. Incidência da Súmula 7/STJ.

VIII. Agravo interno improvido.

(STJ - AgInt no REsp 1577177/AC, Rel. Ministra ASSUSETE MAGALHÃES, SEGUNDA TURMA, julgado em 20/06/2017, DJe 28/06/2017)

GRAVO REGIMENTAL NO AGRAVO (ART. 544 DO CPC) - AÇÃO DE INDENIZAÇÃO POR DANOS MATERIAIS E MORAIS - ERRO MÉDICO RESPONSABILIDADE OBJETIVA DO HOSPITAL - DECISÃO MONOCRÁTICA QUE NEGOU PROVIMENTO AO AGRAVO. INSURGÊNCIA DA RÉ.

1. É plenamente cabível, ainda que se trate de erro médico, acolher a teoria da perda de uma chance para reconhecer a obrigação de indenizar quando verificada, em concreto, a perda da oportunidade de se obter uma vantagem ou de se evitar um prejuízo decorrente de ato ilícito praticado por terceiro.

2. Nos termos da jurisprudência dessa Corte, incide o óbice da súmula $7 /$ STJ no tocante à análise do quantum fixado a título de compensação por danos morais quando não configurado valor ínfimo ou exorbitante.

3. Agravo regimental desprovido.

(STJ - AgRg no AREsp 553.104/RS, Rel. Ministro MARCO BUZZI, QUARTA TURMA, julgado em 01/12/2015, DJe 07/12/2015)

Reflete-se, porém: qual seria então o parâmetro para que a perda de uma chance seja enquadrada ora como um dano patrimonial, ora como um dano extrapatrimonial? 
Rafael Peteffi (SILVA, 2013, p. 162) cita uma manifestação do tribunal de justiça do Rio de Janeiro, quando julgou a demanda proposta por uma pessoa jurídica contra seu antigo advogado, tendo em vista que este havia perdido a oportunidade de recorrer de uma sentença proferida em uma reclamatória trabalhista, em face da intempestividade do recurso interposto.

Consta no acórdão que "estabelecida a certeza de que houve negligência do mandatário, o nexo de causalidade, e estabelecido o resultado prejudicial, demonstrado está o dano moral, haja vista que, segundo a doutrina majoritária, o dano moral advém do próprio fato" ${ }^{11}$.

Neste caso,o fato de a Autora da citada demanda ser pessoa jurídica é importante, pois, como é sabido, apesar de atualmente ser pacífico o entendimento judicial de que as pessoas jurídicas podem sofrer o dano moral ( súmula 227 do STJ ${ }^{12}$ ), tal reparação só é possível em casos específicos.

Nota-se que no caso citado, não é fácil imaginar a ocorrência de dano moral, sendo mais perceptível a existência de dano patrimonial, representado pela condenação pecuniária na demanda trabalhista, decorrente da chance perdida.

Oportunamente, Rafael Peteffi se posiciona no sentido de que a natureza do "dano chance perdida" será a mesma do "dano vantagem esperada", conforme se observa do excerto a seguir:

"Dessa feita, se a vítima esperava ganhar, ao final de uma demanda judicial, 200.000 reais, a perda de uma chance evidentemente terá caráter patrimonial. Do contrário, se a vantagem esperada pela vítima fosse obter a guarda dos filhos, o dano terá caráter extrapatrimonial. Infelizmente a jurisprudência brasileira, seguindo linha bastante difundida em todos os tribunais pátrios que aplicam a teoria da perda de uma chance, não parece seguir esse raciocínio essencial." (SILVA, 2013, p. 162).

$\mathrm{O}$ dano patrimonial refere-se à frustração da obtenção do resultado esperado, que consistiria em um acréscimo patrimonial da vítima. Já o dano moral poderá ocorrer quando os prejuízos pela perda da oportunidade forem relativos à ofensa da pessoa humana. Assim, pode ocorrer a lesão aos dois tipos de interesses, o que acarreta a reparação da chance tanto como dano material quanto extrapatrimonial.

Repare-se também que o voto da ministra Nancy Andrighi no Recurso Especial no 1.079.185 parece ter aplicado de forma clara este raciocínio, ao prever que o Autor da demanda não fazia jus à indenização por danos patrimoniais, já que o bem da vida buscado na demanda judicial patrocinada pelo réu acabou sendo alcançado em demanda posterior.

Constatada a negligência do advogado, poderiam advir daí danos materiais e morais. Os danos materiais descritos na inicial estão atrelados à necessidade de viver de aluguel e ao não

\footnotetext{
${ }^{11}$ RIO DE JANEIRO. Tribunal de justiça do Rio de Janeiro, Apelação Cível no 2003.001.19138, Apelante: Sebastião Carneiro da Silva, apelado: Rapido Monteiro Ltda., Rel. Des. Ferdinaldo Nascimento, julgado em 7-10-2003. In:SILVA, Rafael Peteffi. Responsabilidade civil pela perda de uma chance, p. 162. In: RODRIGUES JÚNIOR, Otávio Luiz; MAMEDE Gladston; ROCHA, Maria Vital da (Coord.). Responsabilidade civil contemporânea: em homenagem a Sílvio de Salvo Venosa. São Paulo: Atlas, 2011.

${ }^{12}$ BRASIL. Superior tribunal de justiça. Súmula 227: A pessoa jurídica pode sofrer dano moral.
} 
recebimento das benfeitorias introduzidas no imóvel o qual foram obrigados a deixar. Como tive oportunidade de ressaltar, a indenização relativa aos aluguéis foi objeto de ação própria, transitada em julgado, não havendo recurso quanto a este ponto. A indenização por benfeitorias, como a própria autora reconhece, foi objeto de terceira ação autônoma, razão pela qual também não pode ser incluída nesta demanda. Assim, o acórdão recorrido caminhou bem ao afastar a indenização por danos materiais. (STJ, Recurso Especial $n^{\circ}$ 1.079.185 MG, Terceira Turma, Rel. Ministra Nancy Andrighi, 4/8/2009.)

Este julgado entendeu pela configuração dos danos morais, pois a perda do prazo recursal também teria acarretado à Autora danos de natureza extrapatrimonial:

Assim, a perda do prazo recursal retirou da recorrente a chance de continuar vivendo naquela residência que, durante longo período, foi sua casa. As consequências nãopatrimoniais daí advindas são muito claras. O infortúnio de perder o lar familiar e a chance de lutar por ele não se reduz a uma expressão econômica. Assim, correta a condenação do recorrido no dever de compensar este dano moral. (STJ, Recurso Especial n $1.079 .185 \mathrm{MG}$, Terceira Turma, Rel. Ministra Nancy Andrighi, julgado em 11/11/2008, DJem 4/8/2009.)

Ademais, ao que parece, pela análise de alguns outros julgados, nos casos em que não estiverem presentes os requisitos para a reparação por chance, por danos materiais, poder-se-ia conceber a reparação por danos extrapatrimoniais, devido à simples frustração da expectativa.

Porém, a adoção de tal posicionamento poderia ensejar reparações irrestritas, pois tutelaria toda e qualquer oportunidade frustrada, sem se preocupar com a seriedade da chance, e muito menos, com a natureza da vantagem esperada.

Agora, permite-se uma outra reflexão: se a perda da chance tiver caráter patrimonial, qual seria a natureza deste dano patrimonial? Nota-se discussão se este dano patrimonial teria natureza de dano emergente, lucros cessantes, ou se na verdade se trataria de uma nova espécie de dano autônomo.

Apenas para relembrar, o dano emergente consiste na efetiva diminuição no patrimônio da vítima, conforme dispõe o art. $402^{13}$ do Código Civil. Vê-se então que o prejuízo é objetivamente identificável.

Os lucros cessantes são o que a vítima razoavelmente deixou de lucrar. É a perda do lucro esperável, há probabilidade objetiva de que o lucro seria o resultado do curso normal. Assim, lucros cessantes correspondem necessariamente a um ganho que ocorreria como consequência do normal.

Mostra-se coerente refletir que o lucro cessante poderia se confundir com a perda da chance, já que ambos os conceitos se relacionam à frustração de uma vantagem esperada.

Todavia, o lucro cessante corresponde à lesão a um bem jurídico que razoavelmente seria incorporado ao patrimônio da vítima no futuro, caso a conduta culposa não tivesse sido praticada. Neste caso, o dano final indenizável é certo, mesmo que o dano não exista no momento contemporâneo de sua visualização.

Já na perda de uma chance o resultado almejado é incerto, mas provável. Neste caso o resultado final depende de diversos fatores, havendo, portanto, somente a probabilidade de que este viesse a se concretizar ao 
final.

Portanto, mostra-se pertinente refletir que a perda de uma chance seria distinta do lucro cessante, pois neste há uma objetiva probabilidade de que o resultado em expectativa aconteceria, caso não ocorresse o dano.

Por outro lado, em relação à perda de uma chance, a expectativa é aleatória, já que havia apenas um grau de probabilidade para a obtenção da vantagem. Não havia grande certeza de que o resultado aconteceria. Logo, na perda de uma chance, não há a absoluta certeza do benefício, mas sim a perda da oportunidade de ter o benefício.

Existem decisões judiciais em que se confunde a reparação pela perda de uma chance com os lucros cessantes. Veja-se:

In casu, tenho que restou comprovada de forma convincente pelos documentos de fls. 230/232-TJ que a apelada seria biomédica, posto que era estudante de biomedicina, sendo incabível a alegação de que à época do acidente a apelada não exercia atividade remunerada. Logo, lucros cessantes ou perda de uma chance afirmo que não se trata de mera expectativa de direito, mas sim de probabilidade objetiva de que a apelada realmente seria biomédica, pelo que devida a indenização.

E nada mais justo do que considerar o piso salarial da categoria no importe de $\mathrm{R} \$ 900,00$ (novecentos reais), visto que seria o provável salário obtido se a apelante estivesse efetivamente trabalhando, motivo pelo qual deve ter crédito o documento oriundo de pesquisa da internet. (TJMG - Apelação Cível 1.0040.05.037062-2/001, Rel. Des.(a) Rogério Medeiros, 14a CÂMARA CÍVEL, julgamento em 05/02/2009, publicação da súmula em 31/03/2009)

No mesmo sentido, recente e atual decisão exarada pelo Superior Tribunal de Justiça:

RECURSOS ESPECIAIS. DIREITO CIVIL E PROCESSUAL CIVIL. RESPONSABILIDADE CIVIL. ART. 535 DO CPC/1973. VIOLAÇÃO. NÃO CONFIGURAÇÃO. ART. 538 DO CPC/1973. AGRAVO DE INSTRUMENTO. MULTA. PRÉVIO RECOLHIMENTO. APELAÇÃO. CONHECIMENTO NÃO CONDICIONADO.

ACIDENTE AUTOMOBILÍSTICO. ATROPELAMENTO. DANOS MATERIAIS, MORAIS E ESTÉTICOS. GRAVIDADE DAS SEQUELAS. CULPA EXCLUSIVA DO CONDUTOR DO VEÍCULO. RESPONSABILIDADE SOLIDÁRIA. PROPRIETÁRIO DO VEÍCULO. CÔNJUGE. AUSÊNCIA DE RESPONSABILIDADE. CAPACIDADE LABORATIVA DA VÍTIMA. REDUÇÃO PERMANENTE. PENSIONAMENTO MENSAL DEVIDO. LIMITES

PEDIDO CERTO E DETERMINADO. DANOS ESTÉTICOS. INDENIZAÇÃO. ARBITRAMENTO. INAPLICABILIDADE DO ART. 1.538, \$1º, DO CÓDIGO CIVIL DE 1916. LUCROS CESSANTES. NÃO COMPROVAÇÃO. TEORIA DA PERDA DE UMA CHANCE. INAPLICABILIDADE NO CASO. DESPESAS MÉDICOHOSPITALARES. RESSARCIMENTO E CUSTEIO. LIMITAÇÃO. PEDIDO INICIAL CERTO E DETERMINADO. REEXAME DE PROVAS. IMPOSSIBILIDADE. SÚMULA No 7/STJ. DENUNCIAÇÃO DA LIDE. RESISTÊNCIA DA SEGURADORA LITISDENUNCIADA. HONORÁRIOS ADVOCATÍCIOS SUCUMBENCIAIS. CABIMENTO. INDENIZAÇÕES POR DANOS MORAIS E ESTÉTICOS. REDUÇÃO. IMPOSSIBILIDADE. RAZOABILIDADE NA FIXAÇÃO. SÚMULA No 7/STJ.JUROS DE MORA. TERMO INICIAL. SÚMULA No 54/STJ.

\footnotetext{
${ }^{13}$ Art. 402. Salvo as exceções expressamente previstas em lei, as perdas e danos devidas ao credor abrangem, além do que ele efetivamente perdeu, o que razoavelmente deixou de lucrar.
} 
1. Ação indenizatória por danos materiais, morais e estéticos suportados por vítima de atropelamento por veículo automotor resultante da ação culposa de seu condutor. Vítima que passou a se locomover com ajuda de aparelhos, sendo acometido de sequelas permanentes em membros superiores e inferiores esquerdos, além de lesão cerebral causadora de falta de atenção e desvio de personalidade. 2. (...) 3. (...) 4. O pensionamento mensal devido à vítima de acidente automobilístico incapacitante deve servir à reparação pela efetiva perda de sua capacidade laborativa, mas deve ser limitado ao pedido certo e determinado eventualmente formulado pelo parte autora em sua petição inicial. 5. A duplicação a que se refere o $\$ 1^{\circ}$ do art. 1.538 do Código Civil de 1916 abrange tão somente a multa penal porventura aplicada ao causador do dano, não podendo ser cumulada com indenização arbitrada para fins de compensação dos danos estéticos suportados pela vítima, sob pena de restar configurada a ocorrência de bis in idem. 6 . A jurisprudência desta Corte admite a responsabilidade civil e o consequente dever de reparação de possíveis prejuízos com fundamento na denominada teoria da perda de uma chance, desde que séria e real a possibilidade de êxito, o que afasta qualquer reparação no caso de uma simples esperança subjetiva ou mera expectativa aleatória. 7. A simples inscrição do autor em concurso público ou o fato de estar, no momento do acidente, bem posicionado em lista classificatória parcial do certame, não indicam existir situação de real possibilidade de êxito capaz de autorizar a aplicação, no caso, da teoria da perda uma chance, não havendo falar, portanto, na existência de lucros cessantes a serem indenizados. 8. Tendo o autor formulado pedido certo e determinado de ressarcimento/custeio de despesas médico-hospitalares, deve a condenação imposta aos requeridos a tal título ser limitada pelos valores por ele indicados na petição inicial, sob pena de se incorrer em julgamento ultra petita. 9. Escapa à competência desta Corte Superior o reexame das circunstâncias fático-probatórias que levaram as instâncias de cognição plena a concluir pela existência de culpa exclusiva do condutor do veículo envolvido no acidente narrado na inicial e de danos materiais indenizáveis, por incidir, na espécie, o óbice da Súmula no 7/STJ.

10. (...) 11. (...) 12. O juros moratórios fluem a partir do evento danoso em caso de responsabilidade extracontratual (Súmula no 54/STJ).13. Recursos especiais parcialmente providos.

(STJ - REsp 1591178/RJ, Rel. Ministro RICARDO VILLAS BÔAS CUEVA, TERCEIRA TURMA, julgado em 25/04/2017, DJe 02/05/2017)

E vê-se que há também o válido posicionamento de que a perda de uma chance seria uma subespécie de dano material emergente, e não de lucros cessantes.

Haverá casos em que a perda da chance, além de causar um dano material, poderá também ser considerada um agregador do dano moral. Por outro lado, haverá casos em que apesar de não ser possível indenizar o dano material, decorrente da perda da chance, em razão da falta de requisitos necessários, será possível conceder uma indenização por danos morais em razão da frustrada expectativa. Frise-se mais uma vez: o que não se pode admitir é considerar o dano da perda da chance como sendo um dano exclusivamente moral, já que, presentes os requisitos, a perda da chance pode dar origem a um dano material, nesta hipótese como dano emergente. (SAVI, 2012, p. 56)

No caso abaixo, advindo do Estado do Paraná, concebeu-se a reparação pela perda da chance, como se fossem danos emergentes. Note-se:

Frise-se, até repetindo, que a indenização por perda da chance, como dito, é decorrente de dano material emergente na medida em que, quando da quebra do contrato, já havia na esfera patrimonial do autor a efetiva probabilidade de lograr êxito na exposição de arte, não se confundido, portanto, com o dano moral.

(PARANÁ. Tribunal de Justiça do Estado do Paraná. Apelação Cível n. o 471.982-0. Quinta 
Câmara Cível. Relator Juiz de Direito Substituto em Segundo Grau Rogério Ribas.

Julgamento: 18 de novembro de 2008.)

No caso acima, parece ter sido dado como certo algo probabilístico, já que na perda de uma chance não se indeniza a vantagem perdida, mas sim a chance de obtê-la.

Perceba-se que se a perda de uma chance estiver sendo considerada como dano emergente ou lucro cessante, terá então o Autor do processo provar, de forma inequívoca que, caso não fosse à existência do ato, o resultado teria se consumado, o que, aparentemente, não será tarefa fácil.

Na perda de uma chance o que se pretende identificar é a probabilidade de uma perda, e não o que a vítima deixou efetivamente de ganhar ou de lucrar (lucro cessante ou dano emergente), respectivamente. Aliás, se assim não fosse, a noção de chance seria absolutamente desnecessária, tendo em vista que já estaria inserida no conceito de lucro cessante ou dano emergente. No julgamento do Recurso Especial n. ${ }^{\text { }}$ 1.190.180, o ministro Luiz Felipe Salomão:

A teoria de perda de uma chance (perte d'une chance) dá suporte à responsabilização do agente causador, não de dano emergente ou lucros cessantes, mas sim de algo que intermedeia um e outro: a perda da possibilidade de buscar posição jurídica mais vantajosa que muito provavelmente alcançaria se não fosse o ato ilícito praticado. Dessa forma, se razoável, séria e real, mas não fluida ou hipotética, a perda da chance é tida por lesão às justas expectativas do indivíduo, então frustradas. (REsp 1.190.180-RS, Rel. Min. Luis Felipe Salomão, julgado em 16/11/2010.)

Outra reflexão que se permite trazer é que a partir de uma mesma conduta do ofensor, o lesado poderia então pleitear a indenização por danos morais, materiais (dano emergente e lucros cessantes), além da perda da chance, o que não configuraria então o bis in idem. Afinal, sabe-se que de um mesmo ato ilícito podem advir resultados e danos diversos.

Vejas-se recente decisão do Superior Tribunal de Justiça, que parece diferenciar danos morai de danos pela perda de uma chance:

AGRAVO INTERNO EM RECURSO ESPECIAL - AÇÃO CONDENATÓRIA PERDA DE UMA CHANCE E DANOS MORAIS - DECISÃO MONOCRÁTICA NEGANDO PROVIMENTO AO RECURSO ESPECIAL. INSURGÊNCIA DA PARTE RÉ. 1. É inviável a análise de teses alegadas apenas em agravo interno - in casu, configuração da prescrição -, mesmo em se tratando de matéria de ordem pública, por se caracterizar inovação recursal, ainda mais quando tais alegações sequer foram analisadas pelas instâncias ordinárias (ausência de prequestionamento).

2. O arbitramento do quantum relativo à indenização pela demonstrada perda da chance bem assim para compensação dos danos extrapatrimoniais deu-se com base no acervo fático-probatório coligido aos autos, não se distanciando, ainda, do parâmetros ditados pelo princípio da razoabilidade. Nesse contexto, a pretensão veiculada no apelo extremo, visando à redução dos aludidos valores, encontra óbice na Súmula 7/STJ. 3. Em atenção ao princípio da unirrecorribilidade recursal, é vedada a interposição de mais de um recurso a fim de impugnar o mesmo decisum. Interpostos três agravos internos em face da mesma decisão, os dois últimos não devem ser conhecidos.

4. Agravo interno de fls. 766-794, e-STJ, conhecido em parte e, na extensão, desprovido. Agravos internos de fls. 795-823 e 824-852, e-STJ, não conhecidos. 
(STJ - AgInt no REsp 1643566/PR, Rel. Ministro MARCO BUZZI, QUARTA TURMA, julgado em 27/06/2017, DJe 01/08/2017)

Assim está no relatório do acórdão acima:

Asseveraram, em síntese, a exorbitância do quantum indenizatório - relativo ao dano extrapatrimonial e àquele decorrente da perda de uma chance - arbitrado na origem, os quais, segundo alegaram, revelam-se contrários aos ditames da razoabilidade, e, outrossim, a inadequação da responsabilização subsidiária de pessoa física, pois tal obrigação apenas exsurge se a pessoa jurídica não a cumprir. Requereram, ao final, a reforma do aresto estadual, "reduzindo o quantum indenizatório, uma vez que a quantia majorada foge dos parâmetros da razoabilidade e fixando-o de acordo com o que o caso realmente demonstrou, retirando a sócia do polo passivo; modificando os danos morais para valores compatíveis com as decisões desta Corte; aplicando corretamente o princípio da razoabilidade para fins de reduzir a condenação pela perda de uma chance."

Constata-se que o tema é instigante e cada vez mais invocado pela doutrina e jurisprudência, merecendo sempre atenção e debate.

\section{Algumas ponderações sobre a mensuração do dano}

\section{Quanto vale a perda da oportunidade?}

Inicialmente, percebe-se que a quantificação dos danos merecerá sempre levar em conta a vantagem esperada, e apurar-se-á a quantia a ser reparada a partir do grau de probabilidade do resultado final que poderia ser alcançado.

Logo, consequentemente, a indenização concedida a título de chance perdida será sempre inferior ao valor da vantagem final.

O caso do Show do milhão, já citado anteriormente, é um bom exemplo, pois o STJ calculou a reparação a partir da vantagem esperada, mediante um percentual correspondente à probabilidade que o ofendido teria de sucesso se a chance não the houvesse sido tolhida.

Mas podem existir casos impossíveis de auferir, imediatamente, quais as chances de sucesso. Acredita-se que nestes casos, a probabilidade poderia ser analisada através de dados estatísticos anteriores. Por exemplo, determinar qual seria o percentual de enfermos que, com determinado tratamento, se recuperariam.

Vale refletir também que os artigos $944^{14} \mathrm{e} 403{ }^{15}$ do Código Civil, possibilitam a reparação integral da chance.

Poderia se cogitar também de um arbitramento, o qual é constantemente utilizado para a apuração dos danos morais. Afinal, a perda de uma chance, a nosso ver, pode também apresentar caráter extrapatrimonial.

No campo patrimonial, o arbitramento pode também ser a única solução em alguns casos. Para isso, é

\footnotetext{
${ }^{14}$ Art. 944. A indenização mede-se pela extensão do dano.

${ }^{15}$ Art. 403. Ainda que a inexecução resulte de dolo do devedor, as perdas e danos só incluem os prejuízos efetivos e os lucros cessantes por efeito dela direto e imediato, sem prejuízo do disposto na lei processual.
} 
necessário que se imagine um caso em que tenha ocorrido a perda de uma chance única e singular de obter um ganho pecuniário, sem que exista qualquer precedente ou parâmetro do qual se possa extrair a probabilidade. A fundamentação da decisão será essencial nestes casos concretos.

\title{
CONCLUSÃO
}

Viu-se que o tema é merecedor de cautelosa análise pelos estudantes do direito e não foi objetivo esgotálo nas linhas acima.

Foi feita uma abordagem geral sobre a teoria da perda de uma chance e sua inserção na seara da responsabilidade civil. E, depois de breve contextualização histórica e evolutiva, apresentaram-se algumas reflexões acerca de sua natureza jurídica, bem como obre sua quantificação, mediante fundamentos legais, jurisprudenciais e doutrinários.

Metodologicamente, adotou-se a linha indutiva para a elaboração da tese, atentando-se à vertente jurídico-dogmática.

Após uma abordagem geral do tema, verifica-se, de forma construtiva, que se divide a doutrina e jurisprudência entre os que defendem o enquadramento da perda de uma chance como espécie de danos emergentes, lucros cessantes, como estritamente modalidade de dano moral ou, ainda, quando dotada esta de caráter patrimonial, como sendo algo intermediário entre os danos emergentes e os lucros cessantes.

Salutar também é a reflexão acerca de como se mensurar a chance perdida, considerando-se as vias de arbitramento e probabilidade.

Assim, vê-se que o tema é mesmo instigante e merece ser aplicado de forma cautelosa e técnica.

\section{RESPONSIBILITY FOR LOSS OF ANY CHANCE: REFLECTIONS ON ITS LEGAL NATURE THAT EVEN PREVENT}

\begin{abstract}
Initially a general approach will be made on the theory of the loss of a chance and its insertion in the field of civil responsibility. After a brief evolutionary historical context, some reflections about its legal nature, as well as its quantification will be presented. Methodologically, the inductive line will be adopted for the elaboration of the thesis, taking care of the legal-dogmatic aspect. In the end, it is intended to denote that the doctrine and jurisprudence is divided between those who defend the framework of the loss of a chance as a kind of emergent damages, loss of profits, as strictly modality of moral damage or, even, when endowed with this patrimonial character, as something intermediate between the emerging damages and the lost profits. In addition, it is intended to show that it is salutary to reflect on how to measure the lost chance, considering the routes of arbitration and probability. It is not intended to exhaust the theme, but rather to raise questions that seem to demonstrate that the subject is indeed very exciting and deserving of deepening doctrine and increasing jurisprudence.
\end{abstract}


Keywords: Loss of a chance; indemnity; civil responsibility; Legal Nature; Materials damage; Off-balance sheet.

\section{BIBLIOGRAFIA}

AMARAL, Ana Claudia Correa Zuin Mattos Do. Responsabilidade Civil Pela Perda da Chance. Ed. Juruá, 2015.

BERNARDINI, Marcos. Responsabilidade Civil. A Perda de Uma Chance No Direito de Trabalho. Ed. Letras Jurídicas, 2017.

BRASIL. Constituição da República. Disponível em: <http://www.planalto.gov.br/presidencia/legislacao>. Acesso em: 10 de jun. de 2013.

Código Civil de 2002. Lei $\mathrm{n}^{\circ} .10 .406$, de 10 de janeiro de 2002. Disponível em: <http://www.planalto.gov.br/ccivil_03/leis/2002/110406.htm>. Acesso em: 10 de jun. de 2013.

Estatuto da Advocacia e a Ordem dos Advogados do Brasil (OAB). Lei no 8.906, de 04 de julho de 1994.

Disponível em: <http://www.planalto.gov.br/ccivil_03/leis/18906.htm>. Acesso em: 10 de jun. de 2013.

Superior Tribunal de Justiça. Recurso Especial n 788.459/BA. Relator: Ministro Fernando Gonçalves.

Julgamento: 08 de nov. de 2005. Disponível em: www.stj.gov.br, acesso em: 10 de Jun. de 2013.

Superior Tribunal de Justiça. Recurso Especial no 821.004/MG. Relator: Ministro Sidnei Beneti. Julgamento: 19 de ago. de 2010. Disponível em: www.stj.gov.br, acesso em: 10 de Jun. de 2013.

Superior Tribunal de Justiça. Recurso Especial n 1.079.185/MG. Relatora: Ministra Nancy Andrighi.

Julgamento: 11 de nov. de 2008. Disponível em: www.stj.gov.br, acesso em: 10 de Jun. de 2013.

Superior Tribunal de Justiça. Recurso Especial no 1.190.180/RS. Relator: Ministro Luis Felipe Salomão. Julgamento: 16 de nov. de 2010. Disponível em: www.stj.gov.br, acesso em: 10 de Jun. de 2013.

Superior Tribunal de Justiça. Recurso Especial no 1.254.141/PR Relatora: Ministra Nancy Andrighi. Julgamento: 04 de dez. de 2012. Disponível em: www.stj.gov.br, acesso em: 10 de Jun. de 2013.

Superior Tribunal de Justiça. Recurso Especial no 1.335.622/MG. Relator: Ministro Ricardo Villas Bôas Cueva. Julgamento: 18 de dez. de 2012.

CAVALIERI FILHO, Sérgio. Programa de responsabilidade civil. 9.ed. São Paulo. Atlas, 2008.

DALLEGRAVE NETO, José Affonso. Responsabilidade civil no Direito do Trabalho. 4. ed. São Paulo: LTr, 2010.

FARIAS, Cristiano Chaves de; ROSENVALD, Nelson. Direito das Obrigações. Rio de Janeiro: Lúmen Júris, 2006 , v. II.

FONSECA, Cristina Maria Nepomuceno da. Responsabilidade pela perda de uma chance: compatibilidade com o sistema jurídico brasileiro e aplicabilidade nas relações de trabalho. Revista LTr: São Paulo, v. 73, n. 10, p. 1272 1280, out. 2009.

GAGLIANO, Pablo Stolze; PAMPLONA FILHO, Rodolfo. Novo Curso de Direito Civil. $6^{a}$ ed. São Paulo: Saraiva, 2008. v. III.

GONÇALVES, Carlos Roberto. Direito civil brasileiro: responsabilidade civil. 7ª Ed. São Paulo: Saraiva, 2012. 
GONDIM, Glenda Gonçalves. Responsabilidade civil: teoria da perda de uma chance. Revista dos Tribunais, v. 94, n. 840, p. 11-36, out. 2005.

A reparação civil na teoria da perda de uma chance. 2010. 187f. Dissertação (Mestrado em Direito) Universidade Federal do Paraná, Programa de Pós-Graduação em Direito, Curitiba.

GONDIM, Glenda Gonçalves e STEINER, Renata Carlos. Responsabilidade Civil Médica: breves considerações em face da recente jurisprudência do Superior Tribunal de Justiça. Revista da Faculdade de Direito da UFG, Goiânia: Universidade Federal de Goiás, v. 33, n.1, 2009.

LANA, Henrique Avelino. Dissolução parcial nas sociedades limitadas: análise econômica sobre a inclusão do aviamento na apuração de haveres. Belo Horizonte: Arraes Editores, 2012.

MINAS GERAIS. Tribunal de Justiça. Apelação Cível no 1.0024.08.102407-7/001, Relator(a): Des.(a) José Marcos Vieira , 16a Câmara Cível, julgamento em 16/05/2013, publicação da súmula em 24/05/2013. Disponível em: <www.tjmg.jus.br >. Acesso em: 10 de jun. de 2012.

Apelação Cível 1.0027.05.068375-7/001, Relator(a): Des.(a) Alberto Henrique , 13a Câmara Cível, julgamento em 03/07/2007, publicação da súmula em 26/07/2008. Disponível em: <www.tjmg.jus.br>. Acesso em: 10 de jun. de 2012.

Apelação Cível no 1.0040.05.037062-2/001. Relator. Des.(a) Rogério Medeiros, 14a Câmara Cível, julgamento em 05/02/2009, publicação da súmula em 31/03/2009. Disponível em: <www.tjmg.jus.br>. Acesso em: 10 de jun. de 2012.

Apelação Cível n 1.0287.09.052904-4/001, Relator(a): Des.(a) Domingos Coelho, 12a Câmara Cível, julgamento em 14/11/2012, publicação da súmula em 26/11/2012. Disponível em: <www.tjmg.jus.br>. Acesso em: 10 de jun. de 2012.

Apelação Cível 1.0324.09.084105-1/001, Relator(a): Des.(a) José Marcos Vieira , 16a Câmara Cível, julgamento em 24/11/2010, publicação da súmula em 03/12/2010. Disponível em: <www.tjmg.jus.br>. Acesso em: 10 de jun. de 2012.

Apelação Cível 1.0569.08.012210-8/001, Relator(a): Des.(a) José Marcos Vieira , 16 a CÂMARA CÍVEL, julgamento em 16/02/2011, publicação da súmula em 25/02/2011. Disponível em: <www.tjmg.jus.br>. Acesso em: 10 de jun. de 2012.

Apelação Cível 1.0699.09.095327-3/001, Relator(a): Des.(a) Nilo Lacerda , 12a Câmara Cível, julgamento em 31/10/2012, publicação da súmula em 12/11/2012. Disponível em: <www.tjmg.jus.br>. Acesso em: 10 de jun. de 2012.

PEREIRA, Caio Mário da Silva. Responsabilidade Civil. 9a ed. Rio de Janeiro: Forense, 2002.

RABELO, César Leandro de Almeida. A responsabilidade civil pela perda de uma chance nas relações jurídicas civis e do trabalho. Revista Síntese Trabalhista e Previdenciária. São Paulo, v. 24, n. 277, p. 22-47, jul. 2012.

RIO DE JANEIRO. Tribunal de Justiça. Apelação Cível n 2008.001.56804, Quarta Câmara Cível, Tribunal de Justiça do RJ, Relatora: Des. Mônica Tolledo De Oliveira, Julgado em 31/03/2009. Disponível em: <www.tjri.jus.br>. Acesso em: 10 de jun. de 2013.

RIO GRANDE DO SUL. Tribunal de Justiça. Apelação Cível no 7004003183370040031833, Décima Sexta Câmara Cível, Tribunal de Justiça do RS, Relatora: Ana Maria NedelScalzilli, Julgado em 27/09/2012. Disponível em: <www.tjrs.jus.br>. Acesso em: 10 de jun. de 2013. 
ROCHA, Vivian de Almeida Sieben. A responsabilidade civil pela perda de uma chance no direito brasileiro. Direito \& justiça, Porto Alegre, v. 36, n.1, p. 45-60, jan./jun. 2010.

RODRIGUES, Silvio. Direito Civil: responsabilidade civil. 20ª ed. São Paulo: Saraiva, 2006. v. IV.

SALLET, Frédérique. La perte de chance dans la jurisprudence administrative relative a la responsabilite de la puissance publique. Paris: LGDJ, 1994.

SANTOS, Antônio Jeová. Dano moral indenizável. 4 ed. São Paulo: Revista dos Tribunais, 2003.

SAVI, Sérgio. Responsabilidade civil por perda de uma chance. São Paulo: Atlas, 2012.

SCHREIBER, Anderson. Comentários ao acórdão do Resp 1.104.665/RS (rel. Min. Massami Uyeda, DJ 04.08.2009). In.: FRAZÃO, Ana et al. (Org). O Superior Tribunal de Justiça e a reconstrução do direito privado. São Paulo: Revista dos Tribunais, 2011.p. 81-102.

SILVA, Cássia Bertassone da. Responsabilidade civil pela perda de uma chance no direito do trabalho. Revista Síntese Trabalhista e Previdenciária. São Paulo, v. 24, n. 277, p. 9-21, jul. 2012.

SILVA, Rafael Peteffi da. Responsabilidade civil pela perda de uma chance. 2.ed. São Paulo: Atlas, 2013.

Responsabilidade civil pela perda de uma chance. In: RODRIGUES JÚNIOR, Otávio Luiz; MAMEDE Gladston; ROCHA, Maria Vital da (Coord.). Responsabilidade civil contemporânea: em homenagem a Sílvio de Salvo Venosa. São Paulo: Atlas, 2011.

TIMM, Luciano Betti. Os grandes modelos de responsabilidade civil no direito privado: da culpa ao risco. Revista de direito do consumidor, São Paulo: RT, v.14, n. 55, 2005.

Trabalho enviado em 05 de julho de 2017.

Aceito em 27 de outubro de 2017. 